\title{
STRATEGI RESOLUSI KONFLIK LAHAN OLEH PT. SURYA BRATASENA PLANTATION DENGAN MASYARAKAT DI KECAMATAN PANGKALAN KURAS KABUPATEN PELALAWAN RIAU
}

\author{
${ }^{1}$ Raja Malinda Jeliantika, ${ }^{2}$ Harapan Tua \\ 1,2, Program Studi IImu Administrasi Publik Fakultas IImu Sosial dan IImu Politik universitas Riau \\ raja.malinda1556@student.unri.ac.id, harapan.tua@lecturer.unri.ac.id \\ Pekanbaru, Riau, Indonesia
}

\begin{abstract}
Conflicts in oil palm plantation companies cannot be separated from land problems with the community. This conflict occurred due to the existence of community land within the PT. Surya Bratasena Plantation due to an error in the previous shaving. The purpose of this research is to see and understand how the company strategy in its efforts to settle land with the community and to find out what factors are the obstacles to the implementation of the Land Conflict Resolution Strategy made by PT. Surya Bratasena Plantation. The theory used in this research is conflict resolution theory with three indicators, namely negotiation, mediation and arbitration. To answer this research problem, researchers used qualitative methods using data collection techniques such as interviews and documentation, then analyzed and looked for conclusions about these problems. The results of this study indicate that the strategy that has been made by PT. Surya Bratasena Plantation and offered to the community can solve the problem without involving a third party in its resolution. The inhibiting factor in carrying out this strategy is the presence of outsiders as provocateurs to make people not want to make peace.
\end{abstract}

Keywords: Agrarian Conflict; Conflict Resolution; Strategy

\begin{abstract}
Abstrak
Konflik di perusahaan perkebunan sawit tidak lepas dari permasalahan lahan dengan masyarakat. Konflik ini terjadi dikarenakan adanya lahan masyarakat di dalam lahan Hak Guna Usaha PT. Surya Bratasena Plantation yang disebabkan kesalahan pada penggukuran terdahulu. Tujuan dari penelitian ini untuk melihat dan memahami bagaimana strategi yang dilakukan oleh perusahaan dalam upaya penyelesaian lahan dengan masyarakat dan untuk mengetahui faktor apa saja yang menjadi penghambat terlaksananya Strategi Resolusi Konflik Lahan yang di buat oleh pihak PT. Surya Bratasena Plantation.Teori yang digunakan didalam penelitan ini yaitu teori resolusi konflik dengan tiga indikator yaitu negosiasi, mediasi, dan arbitrasi. Untuk menjawab permasalahan penelitian ini, peneliti menggunakan metode kualitatif dengan menggunakan teknik pengumpulan data seperti wawancara dan dokumentasi, kemudian akan di analisis dan mencari kesimpulan mengenai permasalahan tersebut. Hasil penelitian ini menunjukkan bahwa strategi yang telah dibuat oleh PT. Surya Bratasena Plantation dan ditawarkan kepada masyarakat bisa menyelesaikan permasalahan tersebut tanpa melibatkan pihak ketiga dalam upaya penyelesaiannya. Adapun faktor penghambat dalam melakukan strategi ini yaitu adanya pihak luar sebagai provokator untuk membuat masyarakat tidak ingin berdamai.
\end{abstract}

Kata Kunci: Konflik Agraria; Resolusi Konflik; Strategi

Open Access at:http://ojs.uho.ac.id/index.php/PUBLICUHO/index

Journal Publicuho is licensed under a Creative Commons Attribution 4.0 International License. 


\section{PENDAHULUAN}

Di Indonesia, permasalahan konflik lahan dengan masyarakat tidak bisa dihindari, tetapi bagaimana cara menyikapi bentuk permasalahan tersebut. Konflik lahan yang sering terjadi yaitu pada perusahaan perkebunan sawit yang menjadi catatan kasus permasalahan konflik lahan yang selalu ada. Konflik terjadi tentu karena adanya masalah yang timbul dengan benturan kepentingan dan keuntungan. Perkembangan yang terjadi pada makhluk social akan selalu berhadapan dengan konflik antar individu maupun kelompok. Konflik juga tidak bisa dihindari tetapi bagaimana cara untuk menyelesaikan dengan berbagai cara yang dilakukan. Seperti yang terjadi antara PT. Surya Bratasena Plantation dengan masyarakat, dimana konflik terjadi karena adanya lahan mereka yang masuk dalam lahan Hak Guna Usaha PT. Surya Bratasena Plantation yang telah dikelola oleh pihak perusahaan tersebut. Kesalahan ini terjadi karena metode pengukuran sebelumnya belum menggunakan alat canggih yang menyebabkan hasil pengukuran lahan sawit tersebut tidak efektif, sehingga sekarang baru menemukan adanya kesalahan yang terjadi yaitu terdapat lahan masyarakat didalamnya.

Dengan adanya permasalahan lahan ini, muncul reaksi dari masyarakat yang meminta haknya kepada pihak PT. Surya Bratasena Plantation dan meminta kejelasan mengenai permasalahan lahan tersebut. Reaksi ini menimbulkan konflik antara pihak PT. Surya Bratasena Plantation dan masyarakat dengan adanya tindakan unjuk rasa yang dilakukan oleh masyarakat. Melihat adanya reaksi yang muncul, pihak PT. Surya Bratasena Plantation ingin menyelesaikan permasalahan tersebut dengan jalur damai. PT juga telah menyiapkan beberapa strategi yang ditawarkan oleh masyarakat agar bisa menyelesaikan konflik tersebut. Bentuk yang dilakukan oleh PT disebut dengan Strategi Resolusi Konflik. Resolusi Konflik itu sendiri yaitu sekumpulan teori dan penyelidikan dalam memahami sifatsifat konflik serta meneliti strategi dilakukan untuk upaya penyelesaiannya. Resolusi Konflik juga menyarankan penggunaan cara-cara yang lebih demokratis untuk menyelesaikan konflik dengan memberikan kesempatan pada pihak-pihak yang memiliki permasalahan tersebut untuk memecahkan masalahnya sendiri tanpa melibatkan pihak ketiga.

Untuk melakukan Strategi Resolusi Konflik, ada beberapa tahap yang dilakukan yaitu negosiasi, mediasi dan arbitrasi. Tahap tersebut dilakukan untuk menyelesaikan suatu konflik guna mencapai kesepakatan bersama dengan cara-cara yang lebih demokratis serta menciptakan hubungan baru yang bertahan lama serat tidak merugikan kedua pihak yang berkonflik.

\section{METODOLOGI}

Penelitian ini menggunakan metode penelitian kualitatif. Menurut Flick (2002), penelitian kualitatif adalah keterkaitan spesifik pada studi hubungan social yang berhubungan dengan 


\section{Journal Publicuho}

ISSN2621-1351 (online), ISSN 2685-0729 (print)

Volume 4 Number 1 (February-April), (2021)pp.171-177

Accredited SINTA SK.NOMOR 28/E/KPT/2019

Open Access at:http://ojs.uho.ac.id/index.php/PUBLICUHO/index

DOI: 10.35817/jpu.v4i1.17012

fakta di dunia kehidupan. Metode ini diterapakn untuk melihat dan memahami subjek dan objek penelitian yang meliputi orang, lembaga berdasarkan fakta yang tampil. Penelitian pada pradigma kualitattif diartikan sebagai suatu proses untuk memahami permasalahan masalah-masalah manusia dengan menciptakan gambaran yang menyeluruh. Peneliti memilih penelitian kualiatatif karena ingin melihat bagaimana strategi yang dilakukan oleh PT. Surya Bratasena Plantation untuk menyelesaikan permasalahan lahan tersebut dan melihat faktor apa saja yang menjadi penghambat dalam proses pelaksanaan Strategi Resolusi Konflik lahan. Dalam penelitian ini, penulis menggunakan teknik pengumpulan data dengan cara wawancara dan dokumentasi

\section{HASIL DAN PEMBAHASAN}

PT. Surya Bratasena Plantation merupakan salah satu perusahaan perkebunan sawit yang berada di Kecamatan Pangkalan Kuras, Kabupaten Pelalawan, tepatnya di Desa Sorek Dua Kecamatan Pangkalan Kuras, yang dikelilingi oleh tujuh desa yaitu Desa Sorek Dua, Batang kulim, Dundangan, Terantang Manuk, Sidomukti, Surya Indah dan Betung. Perusahaan ini sudah beroperasi sejak tahun 1965. Namun, melakukan kegiatan usaha di mulai tahun 1989 , dengan jumlah lahan Hak Guna Usaha seluas 3.200 Ha. Setelah memiliki legalitas Hak Guna Usaha tersebut, maka pabrik mulai beroperasi. Dalam kegiatan perusahaan sawit tersebut terjadi kekeliruan dalam pengukuran lahan. Ada sebanyak 844 Ha lahan masyarakat didalam Hak Guna Usaha PT. Surya Bratasena Plantation. Hal ini menimbulkan konflik dengan masyarakat karena merasa ada yang tidak terbuka mengenai permasalahan tersebut. Untuk itu, agar konflik tidak berlanjut dan melewati proses hukum, maka pihak PT. Surya Bratasena Plantation ingin menyelesaikan konflik ini dengan cara damai melalui strategi yang telah dibuat oleh PT. Surya Bratasena Plantation. Strategi ini diharapkan mampu untuk mengaatasi permasalahan tersebut dan tetap menjalin hubungan baik dengan masyarakat.

\section{Strategi Resolusi Konflik Lahan Oleh PT. Surya Bratasena Plantation Dengan Masyarakat Di Kecamatan Pangkalan Kuras, Kabupaten Pelalawan Riau}

Penelitian ini ingin melihat bagaimana strategi yang dibuat oleh PT. Surya Bratasena Plantation untuk ditawarkan kepada masyarakat sesuai dengan tujuan dari penelitian ini. Untuk mengetahui mengenai strategi ini, peneliti melakukan wawancara kepada informan dengan menggunakan 3 indikator menurut Fisher (dalam fina 2017) diantaranya yaitu Negosiasi, Mediasi dan Arbitrasi. Berikut penjelasannya.

\section{Negosiasi}

Negosiasi merupakan suatu proses pemecahan masalah secara sukarela antara pihak yang berkonflik untuk menyelesaikan permasalahan mereka oleh mereka sendiri. Negosiasi menuntut pemahaman ketrampilan dalam melakukan upaya penyelesaian permasalahan konflik lahan seperti didalam penelitian ini. Negosiasi ini juga sebagai awal dari komunikasi 
ISSN2621-1351 (online), ISSN 2685-0729 (print

Volume 4 Number 1 (February-April), (2021)pp.171-177

Raja Malinda Jeliantika, Harapan Tua

DOI: 10.35817/jpu.v4i1.17012

antara pihak PT. Surya Bratasena Plantation dengan masyarakat untuk membahasa perincian dari masalah yang sedang terjadi agar tidak terjadinya kesalahpahaman diantara kedua pihak tersebut. Dalam hal ini, bentuk negosiasi yang terjadi antara pihak PT. Surya Bratasena Plantation dengan masyarakat yaitu dilakukannya komunikasi dua arah untuk mencapai kesepakatan dan tujuan bersama dengan menghasilkan strategi yang akan digunakan yaitu metode Tukar Gulung dan Ganti Rugi. Metode yang ditawarkan ini, akan dipilih masyarakat untuk menentukan keputusannya dalam penyelesaian konflik ini.

\section{Mediasi}

Mediasi merupakan strategi pada resolusi konflik dalam melakukan penyelesaian permasalahan melalui pihak ketiga sebagai pihak netral yang membantu pihak-pihak yang berkonflik dengan tujuan untuk mengidentifikasi dan memecahkan permasalahan mereka. Dalam melakukan mediasi, tentunya ada mediator sebagai pihak ketiga seerti didalam penelitian ini, yang menjadi mediator dari permasalahan konflik lahan yaitu perangkat desa. Yang mana, perangkat desa sebagai penengah dan memfasilitasi kebutuhan tempat untuk menjembatani pertemuan antara pihak PT. Surya Bratasena Plantation dengan masyarakat. Pihak desa dipilih sebagai mediator dikarenakan lahan tersebut berada diwilayah ketiga desa, seperti Desa Sorek 1. Desa Sorek 2 dan Desa Batang Kulim.

\section{Arbitrasi}

Arbitrasi sebagai strategi resolusi konflik melibatkan pihak ketiga yang bersifat netral. Tetapi, metode arbitrasi, pihak ketiga mempunyai otoritas untuk menentukan hasil yang harus dipatuhi oleh pihak-pihak yang berkonflik. Arbitrasi ini berbeda denagan pihak ketiga yang berada di tahap mediasi. Mediasi mempunyai pihak ketida tetap tidak mempunyai kewenangan dalam menentukan hasil dari penyelesaiannya. Didalam penelitian ini, metode arbitrasi tidak jadi digunakan, karena pihak PT. Surya Bratasena Plantaion ingin menyelesaikan konflik ini dengan cara damai tanpa melibatkan pihak ketiga.

\section{Metode Penyelesaian Oleh PT. Surya Bratasena Plantation}

Dalam upaya untuk melakukan penyelesaian konflik lahan dengan masyarakat, pihak PT. Surya Bratasena Plantation membuat metode yang akan ditawarkan oleh masyarakat, Metode ini diharapkan bisa mencipatakn hubungan baru dalam bentuk kerjasama sesuai dengan pilihan yang akan diambil oleh masyarakat. Berikut dipaparkan dua metode yang dibuat oleh PT. Surya Bratasena Plantation, yaitu:

1. Tukar Guling

Metode Tukar Guling ini adalah suatu metode pergantian lahan yang diberikan oleh pihak PT. Surya Bratasena Plantation kepada masyarakat agar lahan mereka tidak didalam Hak Guna Usaha PT dan di pindahkan ke tempat yang lain. Dalam pengelolaannya, lahan tersebut dibawah pengawasan PT. Surya Bratasena Plantation dengan sistem kerjasama mitra oleh Kelompok Tani. Tukar Guling ini nantinya akan 


\section{Journal Publicuho}

ISSN2621-1351 (online), ISSN 2685-0729 (print)

menghasilkan penghasilan yang telah di olah oleh PT dan masyarakat tinggal menerimanya. Kelompok Tani yang dimaksud ialah sebagai wadah dari msayarakat yang memilih metode Tukar Guling dan tempat penghubung komunikasi antara PT dan masyarakat. Hasil dari panen, akan diserahkan kepada Kelompok Tani dan dibagikan kepada masyarakat. Kelompok Tani ini bisa disebut sebagai perwakilan dari masyarakat kepada PT. Surya Bratasena Plantation.

2. Ganti Rugi

Metode ganti rugi disini ialah sistem yang dilakukan dengan memberikan uang ganti rugi, tetapi dalam status kepemilikan lahan, jika memilih ini akan menjadi sepenuhnya milik PT. Surya Bratasena Plantation. Bentuk dari ganti rugi yang telah dilakukan oleh PT hanya sebagai cost social yang diberikan kepada pemangku ada setempat sebagai tanda penyelesaian konflik ini dengan cara damai. Cost social ini juga ada berupa bantuan kepada pihak desa.

Faktor Penghambat Proses Strategi Resolusi konflik Lahan Oleh PT. Surya Bratasena Plantation Dengan Masyarakat di Kecamatan Pangkalan Kuras, Kabupaten Pelalawan Riau

Dalam melakukan setiap rencana, pasti adanya hambatan yang terjadi dalam pelaksanaannya. Ini tidak bisa dipungkiri meskipun sudah dilakukan dengan baik tentu ada yang menjadi penghambatnya. Berdasarkan hasil penelitian yang dilakukan oleh penulis, menemukan faktor-faktor penghambat dalam melaksanakan strategi resolusi konflik lahan sebagai berikut :

\section{Kurang Tertibnya Adminsitrasi}

Tertib administrasi menjadi kunci utama dalam keberhasilan penyelenggaraan pemerintahan. Jika administrasi tidak tertib maka akan terjadi kekacavan yang membuat instansi atau organisasi melakukan kesulitan dan kinerjanya menajdi terhambat akibat administrasi yang kacau, apalagi administrasi mengenai lahan. Dalam penelitian ini, di akibatkan dari pengukuran yang kurang tepat sehingga membuat kekacauan pada sistem lahan.

\section{Adanya Provokasi Dari Pihak Lain}

Seperti yang terjadi dilapangan, peneliti melihat bahwa setiap permasalahan tentunya ada pihak yang pro dan kontra. Tekait dengan masalah dalam peneitian ini, untuk menentukan pilihan masyarakat mengenai metode strategi apa yang akan di ambil maka banyak yang memanfaatkan keadaan tersebut agar masyarat lama membuat keputusan. Sementara pihak PT. Surya Bratasena Plantation ingin menyelesaikan kasus tersebut dengan cepat. Adanya provokasi ini membuat masyarakat bingung terhadap langkah apa yang akan digunakan.

\section{Keinginan Masyarakat Tidak Sesuai Dengan Keputusan PT. Surya Bratasena Plantation}


ISSN2621-1351 (online), ISSN 2685-0729 (print

Volume 4 Number 1 (February-April), (2021)pp.171-177

Raja Malinda Jeliantika, Harapan Tua DOI: 10.35817/jpu.v4i1.17012

Keinginan dan tujuan masing-masing pihak tentu berbeda-beda. Mengenai permasalahan ini, terjadi perbedaan pendapat yang membuat kedua pihak tidak mau mengalah dan memepertahankan keinginan masing-masing. Dalam hal ini, pihak PT menunguu keputusan masyarakat dengan tetap mempertahankan metode yang telah ditawarkan. Jika masyarakat belum membuat keputusan, maka PT tetap akan menunggu.

\section{Metode Penyelesaian Hanya di Tentukan Oleh PT. Surya Bratasena Plantation}

Pada penyelesaian konflik lahan ini, hanya mengikuti metode yang telah ditawarkan oleh pihak PT. Surya Bratasena Plantation dan masyarakat yang ingin menyelesaikan konflik dengan mengikuti bentuk metode penyelesainnya. Hal ini terasa tidak adil untuk masyarakat, padahal pada tahap awal dilaksanakan negosiasi. Negosiasi ini berperan untuk saling medengarkan apa saja dari keinginan masing-masing pihak, tetapi kenyataan dilapangan dimana negosiasi hanya dari pihak PT. Surya Bratasena Plantation yang menawarkan metode bentuk penyelesaiannya yang seakan-akan memaksa masyarakat untuk mengikuti arahan dari pihak PT. Surya Bratasena Plantation

\section{KESIMPULAN}

Berdasarkan hasil penelitian yang dilakukan oleh peneliti mengenai Strategi Resolusi Konflik Lahan Oleh PT. Surya Bratasena Plantation Dengan Masyarakat di Kecamatan Pangkalan Kuras Kabupaten Pelalawan Riau, maka penulis akan memberikan kesimpulan sebagai berikut :

1. Dalam pelaksanaan Strategi Resolusi Konflik Lahan berjalan dengan baik sesuai dengan tujuan yang diinginkan walaupun masih ada beberapa masyarakat yang belum menentukan pilihan metode strategi apa yang akan dipilih untuk menyelesaikan kasus tersebut. Dilihat dari perindikatornya mengenai strategi resolusi dengan tahap pertama yaitu Negosiasi. Tahap ini sudah dilakukan oleh pihak PT. Surya Bratasena Plantation dengan melakukan komunikasi mengenai permasalahan tersebut dan membicarakan langkah-langkah apa yang akan digunakan. Kedua yaitu Mediasi, mediasi ini menghadirkan pihak ketiga yang bersifat netral dengan melibatkan pihak desa sebagai pihak yang menjembatani kedua pihak yang berkonflik. Ketiga ada arbitrasi, dimana dalam kasus ini tidak jadi digunakan, karena masyarakat mau melalui cara damai untuk menyelesaikan kasus ini.

2. Dalam pelaksanaan Strategi Resolusi Konflik ini, tentu ada faktor yang menjadi penghambat terlaksananya proses resolusi konfllik yaitu kurang tertibnya administrasi, adanya provokasi dari pihak luar, keinginan masyarakat yang tidak sesuai serta metode yang ditawakan hanya ditentukan oleh pihak PT. Surya Bratasena Plantation yang membuat terhambatnya strategi ini dilaksanakan. 


\section{Journal Publicuho}

ISSN2621-1351 (online), ISSN 2685-0729 (print)

Volume 4 Number 1 (February-April), (2021)pp.171-177

Accredited SINTA SK.NOMOR 28/E/KPT/2019

Open Access at:http://ojs.uho.ac.id/index.php/PUBLICUHO/index DOI: 10.35817/jpu.v4i1.17012

Saran dalam permasalahan ini, perlu adanya komunikasi lebih lanjut dari pihak PT. Surya Bratasena Plantation agar masyarakat memahami permasalahan yang ada dan tidak saling menyalahkan satu dan lainnya. Masyarakat disini mudah terpengaruh oleh pihak luar yang memanfaatkan keadaan, untuk itu masyarakat harus dibimbing dan diberikan sosialisai megenai metode yang ditawarkan, serta dalam membuat metode tersebut, seharusnya juga mendengarkan masyarakat dan tidak membuatnya sepihak.

\section{DAFTAR PUSTAKA}

Adiansyah, W. Apsari. (2019). "Resolusi Konflik Agraria di Desa Genteng Kecamatan Sukasari Kabupaten Sumedang" Jurnal Kolaborasi Resolusi Konflik, 1 (1)

Alamsah D Nandang. (2018). Adminsitrasi Pertanahan. Tanggerang Selatan: Universitas Terbuka

Ardani, M.N. (2019). "Penyelenggaraan Tertib Administrasi Bidang Pertanahan Untuk Menunjang Pelaksanaan Kewenangan, Tugas dan Fungsi Badan Pertanahan Nasional" Adminsitrative Law and Governance Journal, 476-492

Crawly, John and Graham, K. (2002). Mediation for Manegers: Penyelesaian Konflik dan Pemulihan kembali Hubungan Tempat Kerja. Jakarta: Bhuana Ilmu Populer, Kelompok Media

Fisher Simon, Jawed Ludin, Steve Williams dkk. (2000) mengelola Konflik. Indonesia: SMK Grafika Desa Putra

Hendricks, Wiliam. (1996). Bagaimana Mengelola Konflik. Petunjuk Praktis Untuk Manajemen Konflik Yang Efektif, Jakarta: Bumi Aksara

Imam Gunawan. (2016). Metode Penelitian Kualitatif: Teori dan Praktek. Jakarta: Bumi Aksara

M. Mukhsin Jamil. (2007). Mengelola Konflik Membangun Damai (Teori Strategi dan Implementasi Resolusi Konflik. Semarang: Walisongo Mediation Centre

Maria S.W. Sumardjono. (2008). Mediasi Sengketa Tanah (Potensi Penerapan Alternatif Penyelesaian Sengketa di Bidang Pertanahan. Jakarta: Ghalia Indonesia

Hamid, I. Tina. (2015). "Konflik Agraria dan Jalan Keluarnya Konflik PTPN XIV Dengan Masyarakat Polongbangkeng-Takalar dan Keera Wajo" Jurnal Konflik Agraria, 4(2):141-148

Kurniati Nia. (2016). Hukum Agraria Sengketa Pertanahan. Bandung: PT. Refika Aditama

Lombong, Bernhard. (2012). Konflik Pertanahan. Jakarta: CV Raffi Maju Mandiri

Sudira, I.N. (2017). "Resolusi Konflik Dalam Perubahan Dunia Global" Jurnal Politik Internasioanl, 19(2)

Syafi, I. (2016). "Konflik Agraria di Indonesia: Catatan Reflektif Konflik Perkebunan Sawit di Kota Waringin Timur" Jurnal Masyarakat dan Budata, 18(3): 415-432

Wahyu, Akdan. (2005). Manajemen Konflik Dalam Organisasi. Bandung: Alfabeta 